\title{
How to be novel and unique in the creation of choreographers
}

\author{
Zhuang Jingwen \\ Tourism and civil aviation management institute,Haikou College of Economics,Haikou,571127,China
}

Keywords: Novel, Choreography, Dancer, Unique.

\begin{abstract}
With the social development process continues accelerating, in the current new era, people's quality of life is also constantly improved.On the basis of meeting the basic spiritual needs of life, people put forward higher requirements for the overall performance of dance.As a key part of the formation of excellent dance works, the quality of choreographers has a direct impact on the level of dance works. Therefore, by improving the novelty and uniqueness in the creation of choreographers, it is possible to greatly change the manifestation of the whole dance, which has an important effect on improving the quality. Based on this, this paper mainly expounds the significance of dance, analyzes the current situation of the dance creation in our country, and targeted to put forward strategies on how to improve the novelty and uniqueness in the creation of choreographers. In order to be able to guide our country's choreography better with novelty and uniqueness, to provide theoretical references.

The creation of choreographers directly determines the success of a dance work. Therefore, it is necessary for choreographers to be at a good overall quality of dance. Choreography affects the whole works in the process of the dance creation. I believe that competent choreographers should be equipped with the ability of organization, structure, language expression and dance rehearsals, in order to carry out work effectively. The performance of dance is more special, not immutable. It is not limited to the written language, and dancers can strengthen their emotional communication through dancing. The use of beautiful dance better shows the emotional tendency of dance in the specific time and space. So people usually show the composition of dance as action, rhythm and expression. The movement of the human body is a means of expression for the dance, without a certain purpose. It mainly uses the artistic expression of dance to reflect the emotional life to be expressed. Because of this, as a choreographer, we need to be better novel, unique and innovative in the creation of works.
\end{abstract}

\section{The cultural significance of dance}

Based on the essential concept of dance, the economic material in the area of dance directly determines the cultural connotation of dance. To some extent, the existence of cultural connotation also directly reflects the economic, political and social customs of the region. Dance exists in the form of a cultural product, and is embodied by artistic expression. In other words, dance is derived from people's daily life style and emotions. But dance is performed by means of cultured and refined, while beyond life. So it's the distillation of people's lives[2].

Therefore, as a kind of spiritual and cultural product after artistic treatment, there are two main meanings in dance culture.

On the one hand, as a cultural product, dance helps people's spiritual world change in the process of unconscious. Generally speaking, the excellent dance works created by choreographer help to wash people's mind and make people's spirit more pleasant, thus forming a good attitude [3].In addition, under the influence of the excellent dance culture for a long time, people's sentiment and soul can be influenced and cultivated in a subtle way. Thus, in the atmosphere of spiritual enrichment and happiness, the cohesion and centripetal force of people can be enhanced, and people's sense of national identity and belonging can be improved. 
On the other hand, as a form of culture, excellent dance culture helps to promote the continuous development of economy in return. Marxism believes that economic material level is the basis of cultural development [4]. In other words, the decisive factor for the development of local culture is the local economic and material level. In addition, the level of local economic development can also be reflected by the content and form of culture. Therefore, the local economy and politics will also be influenced by local culture. It can be said that culture and economy are interdependent and closely linked [5].The cultural reaction is mainly manifested in the following two aspects: First, the development of culture helps to strengthen the relationship and blend with the economy, and even form a certain cultural industry chain, so as to add new impetus to the development of the local economy. Second, cultural development helps to promote the construction of political civilization in this area further, and it is more conducive to the construction of a socialist harmonious society.

\section{The present creation situation of choreographers}

The existence of dance with a large special performance is different from other forms of expression. In the process of dance creation, dancers can use their imagination and physical expression to reflect their thoughts. In a sense, excellent dance works greatly edify the viewer and dancer's own sentiment [6].Besides, dance is also an aesthetic way of expression and communication. Excellent communication works will inevitably lead to emotional resonance of the audience, make people feel touched, and cause a certain impact on the corresponding behavior of the audience.

Compared with the past, China's dance industry has undergone many changes in recent years, the development is very fast. At present, China's domestic dance types are more diverse. The professional choreographers are more and more popular. The expressive power of dance is constantly improving. With the development of society, the performance of dance is also moving with times. However, there are still problems in the current choreographer. Specifically, it mainly displays in the following sides[7]: One is the lack of professional ethics accomplishment of choreography staffs. They usually focus on simple body movements in the process of choreographing. The second is the lack of a certain cognition of connotation relationship in their dance. In the process of creation, they often used to use the usual thinking to show dance movements, ignoring the internal thinking of dance communication. Therefore, the whole expressive force of dance lacks some coordination. The third is the choreographers themselves lack professional moral accomplishment, which leading to the situation that dance movements of some of the practitioners are irregular and uncoordinated.

Therefore, choreographers should pay attention to improving personal professional knowledge and moral accomplishment. Getting rid of the unrealistic phenomena in the process of creation. Creating excellent works that can guide people to choose the right value orientation and make progress in according with the fine tradition and traditional virtues of the Chinese nation and the reality. Besides, there should be some moral educational significance in excellent dance works. So that people can feel the thought of dance creators in the process of appreciating the dance imperceptibly, improving the appreciation of the aesthetic level of the audience.

\section{How to improve the creative features of choreographer}

To show the distinctive theme based on life. Well-known scholar Marx once said that all our crystallization of ideas are derived from social life. Although the performance of dance requires unique innovation, but it cannot be divorced from life. Dance creation, out of life, is unable to arouse the audience's sympathy in any nation, country and region. Like the Miao, Dai and Han nationalities in China, different nationalities have different ways of expressing their dances, and the connotation of dance is also different. Therefore, in the cultural occasions of dance, the cultural themes that have lasted for thousands of years reflect the different social and cultural life. Thus, in the choreography, you need to have the detailed observation, thinking of all aspects of life.

The themes and connotations of different dances are different. But as long as it is the theme of 
infinite love for life, it will be popular in the dance performance. Such as the dance works "Dunhuang sculptures". By shaping a group of all kinds of young girls, showing a group of beautiful flying girl. They use graceful dancing to show the beauty of the dance. So that the audience will not only see the beauty, but also feel the unique charm of women at the same time. It shows the long history of our country's development and culture, reflects the people's love for life. This kind of work highlights the distinctive theme of dance. Of course, it is loved by the audience. There are some works that express dissatisfaction with life. And it usually causes people to rethink and look forward to life, and usually gives people more inner shocks.

"Emotion" is usually a touching word that affects people's inner feelings. Thus in the creation of the dance drama process, it is necessary for choreographers to integrate into a variety of emotions to impress the audience. No matter how cool the visual impact is, if there is a lack of real emotion, then it will be unable to lead the audience sympathy. Therefore, on the basis of paying attention to the theme of dance, we should make the dance to be emotional. Thus greatly arouses the emotion of the audience. And that is exact our life.

Although dance originates from life, but as a sublimation of life, dance should go beyond life. Therefore, the choreographers should improve the ability of refining life and the consciousness of innovation. They should be good at refining the beauty of various phenomena in life from different angles and record its unique body language in written form. Sublimating it into an art and finding better professional materials, avoiding following others blindly and better to serve the audience.

Innovating the thinking of choreographers and broaden their views. Some people say that excellent works are usually based on the basis of others and finished by imitating. Students will also have the presence of essay in writing. You will have the ability to write after the number of imitation. But that's not the case. It's not possible to create innovative works for a long time if you copy mechanically. Choreographer needs to read a large number of dance examples in daily creation. By watching a large number of dance works, you can keep the characteristics of the dance works in mind. Introducing such characteristics into your creation can be called imitation. The process can also be a process of opening up horizons. But what we need to pay attention to is we should be innovative in this process and feel ourselves in the sublimation, making the creations of our own more special. If choreographers can better achieve innovation in creation, then it is necessary to accumulate a large number of dance works. Broadening the horizon through the analysis of the dance works.

With the continuous development of society, the audience's aesthetic indicators are constantly changing. Therefore, it is necessary for choreographer to integrate their own views into the correct values. Integrating the true, good and beauty in the dance creation plays an important role in correcting people's values. The forward thinking refers to integrating the observation of life phenomenon into the dance creation directly, rather than indirectly. While, the reverse thinking means that we should excavate the artistic factors from different angles, or think about the problem from the opposite point of view, to achieve unexpected effect. In addition, we should excavate and make use of the knowledge which is not involved in the field. For example, the creator of the dance "The lovely peacock "make full use of modern high-tech special effects to unite the dancers and peacocks perfectly rather than presenting the ancient folk dance directly to the stage, which makes the charm of dance get a greater show. It can be seen that choreographers should be good at using individual thinking to improve the ability of innovating and creating, to show their own personalities and characteristics. Therefore, the choreographers should also have the ability to choose legitimately. Out of the traditional way of thinking and integrating the abstract content into the creative process, so that the audience will feel refreshing.

Be innovative and unique in your style. In general, many of the most popular dance works filled of the spirit of the times are the praise of noble thoughts and character. It mainly expresses people's pursuit of good things and the expression of their wishes. In addition, excellent dance works can increase their content to an idealized height to help to clean people's minds thus arouse people's sympathy. As an artistic form of telling with body movements, the focus of dance is not narrating, but express emotions. However, due to the influence of many factors, dance 
choreography created by choreographer is not a rehearsal of the whole social life. But through the use of artistic expression, the creator has enough imagination and complex space. Therefore, in order to pass the flesh and blood information to the audience, the choreographers should fully understand and master the dance action, amplitude and angle, and constantly improve their artistic talent.

\section{References}

[1] Jin Ke.How to Strive for Originality and Uniqueness in the Creation of Choreographers[J].The Beauty, Times and City, 2014(8):88-88.

[2] Zhang Na.An Analysis on How Choreographers Create Innovative and Unique Dance[J].Travel overview journal, 2015(1).

[3] Hu Xiaojun. How to Strive for Innovation and Uniqueness in the Creation of Choreographers[J].Voice of the Yellow River, 2012(16):79-79.

[4] Lv Weixiao, Tan Xian.How to Make Novels Unique in the Creation of Dance[J].Pure child: Mid,2014(23):49-49.

[5] Tong Suzhongwu.How to Strive for Innovation and Uniqueness in the Creation of Choreographers[J].Popular literature and art,2016(11):160-160.

[6] Zhang Yixin.An Analysis on How Choreographers Create Innovative and Unique Dance[J].Drama home, 2016(2):142-142.

[7] Hu Haoqi.How to Strive for Innovation and Uniqueness in the Creation of Choreographers[J].Drama home,2016(17):162-162.

[8] Miao Xiaoping.How to Strive for Innovation and Uniqueness in the Creation of Choreographers[J].Journal of Decision and Information,2016(3):100-100. 